\title{
Experience of a Medical Student: Volunteering in The Emergency Department during Massive Flood in Kelantan, Malaysia
}

Zhi Xiong Chong.'

\section{The Experience}

About the Author: Zhi Xiong Chong is currently a final-year medical student of a five-year medical programme at the school of Medical Sciences, Universiti Sains Malaysia, Kelantan, Malaysia. He is the winner of the scientific poster competition at the East Asian Medical Student Conference (EAMSC) in Japan in 2013.
On December 2014, a massive flood happened in the state of Kelantan, Malaysia. It was recorded as the most significant and disastrous flood in Kelantan. The government estimated around 200,000 people were affected. 'The hospital of Universiti Sains Malaysia (HUSM) became the only unaffected and functioning hospital in the state of Kelantan (Himanshu B. HUSM the only fully functioning hospital left in Kelantan. The Malaysian Insider. Available from: http://www.themalaysianinsider. com/malaysia/article/husm-the-only-fully-functioning-hospital-left-in-kelantan.\#sthash.8crkGgMz.dpuf. Updated: 2015 Feb 1; cited: 2015 Mar 27).' HUSM received around 1000 patients in a day in which $10 \%$ of them were critically-ill referred from other affected district hospitals. More than $50 \%$ of the staff from the emergency department (ED) was affected and unable to turn up for work. The ED faced shortage of staff to handle the huge number of patients.'

Following that, the school of medical sciences at Universiti Sains Malaysia declared a week of holiday for all medical students and urged everyone to help the hospital to face this crisis (Himanshu B. HUSM the only fully functioning hospital left in Kelantan. The Malaysian Insider. Available from: http://www.themalaysianinsider.com/malaysia/article/husm-the-only-fully-functioning-hospital-left-in-kelantan.\#sthash.8crkGgMz.dpuf. Updated: 2015 Feb 1; cited: 2015 Mar 27). I was one of the medical students who volunteered to help in the ED.

Being affected by flood can cause many types of physical injuries and infectious diseases to the victims. ${ }^{2}$ According to a study, common physical injuries include abrasions and fractures. ${ }^{3}$ The ED was fully loaded with patients who were injured during the flood while they tried to escape the rising water. I helped in cleaning their wounds and made simple dressings. I also had the chance to assist the medical officers to reduce and manipulate fractures and help with splinting. It became so meaningful that we can apply our knowledge and skills in real situation to help the flood victims. The satisfactory feeling was awesome!

The Importance of Triage

Dilemma occurred when the number of casualty exceeded the capacity of available ED staffs and volunteers. Many patients called for help and we were unable to help all of them at the same time. We had to triage them properly and attended each of them based on the clinical severity. As a volunteer, I felt sorry to be unable to help all of them at the same time.

\section{Flood and infection}

A study conducted in Vietnam has shown that prevalence of communicable diseases such as infective diarrhoea and leptospirosis increased during and after flood in tropical weather. ${ }^{4}$ The same phenomenon happened in Kelantan whereby many patients were having infective diarrhoea. As a volunteer, I helped to keep them hydrated and helped the staff to monitor their vital signs. Sometimes I managed to get short history from them and presented it to the medical officers. When I had more free time, I became an educator and taught the victims about the mode of transmission of communicable diseases and personal hygiene to prevent disease transmission. I hope this could improve their understanding of the pathophysiology of infections, so that when they get back to their homes after the flood has subsided, they would optimize their conditions to reduce the rate of infectious transmission. Another study has shown that good hydration, close monitoring and education are the important steps to reduce mortality rate caused by infective diarrhoea and reduce its transmission. ${ }^{3}$ I was happy because I was able to educate them based on what I have learnt before.

Figure 1. A Flooded Village in the Kuala Krai Distinct, State of Kelantan, Malaysia.

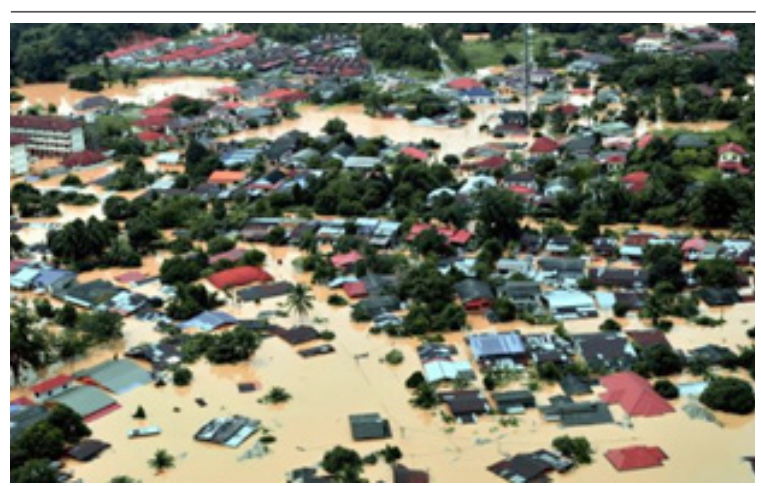


Figure 1. Sultan Muhammad V Stadium in Kota Bharu, the capital of the state of Kelantan, Malaysia, after Flood.

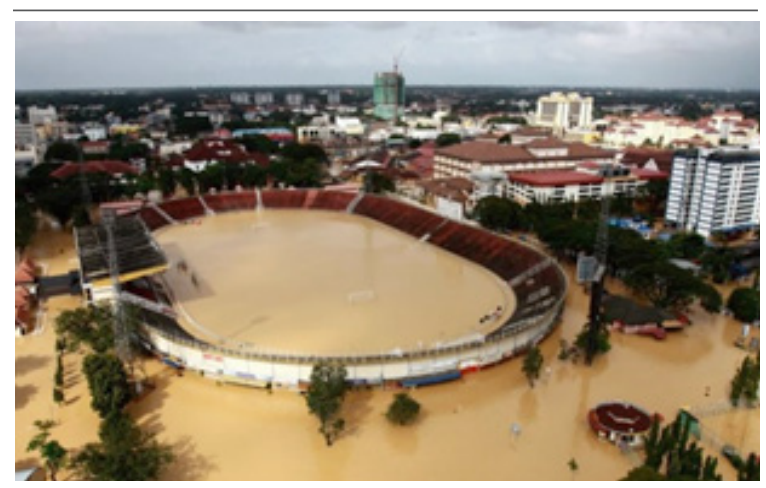

Most Touching Story of that Day

There was a sad case which I had encountered in the ED. A woman lost her husband who drowned after he attempted to save their son who fell from a boat. The family was brought by the rescue team to the ED. The team performed cardiopulmonary resuscitation (CPR) on both of the husband and the son along the way to the hospital. My team tried their best to save them but failed. The woman kept compressing the chest of her son after the paramedics had stopped the resuscitation. We had to pull her away and to give her comfort to calm her down. The moment was so disheartening. Life is so fragile and we can never expect what would happen in the next second.

\section{Other Consequences of Flood}

Flood also causes damages to the properties. ${ }^{5}$ A study has shown that flood can cause significant negative impact to the economics of a country by destroying the infrastructure and properties of the citizens. The study also demonstrated a significant association between socio-economic impact and mental illness among the flood survivors. ${ }^{5}$ As a volunteer in the ED, I also act as a counsellor. Most patients were sad as their homes were destroyed by the flood. Some patients were reluctant to leave the ED as they did not know where to go. I empathized with them and tried to talk to them. I gave them moral support and motivation to help them get through this difficulty time. I became an active listener of their problems and provided personal suggestions to help them solve the problems they presented with. I thought they needed someone to talk to them to release their tension. I wonder if some of them would suffer from Post-Traumatic Stress Disorder (PTSD) in the future and I really hoped they would be fine. Some studies have shown that PTSD became one of the commonest mental health issues among the flood survivors. ${ }^{3.4} \mathrm{As}$ for complicated cases, I would find psychologist to talk to them.

\section{Why to Volunteer in the ED?}

In addition, helping in the ED enabled me to assist and gain experiences in many clinical procedures such as suturing, urethral catheterisation, central line insertion, nasogastric tube insertion and so on. I learned theoretically most of these procedures before but never had a chance to perform them in real life. Due to the shortages of staff, I was called by the doctors to assist them in the procedures and I was really thankful to the supervision and guidance given by them.

Volunteering in the ED was a great experience for me, and hopefully it would help me to become a better doctor in the future. Medical students alike should grab the opportunity at any time, especially during disasters, to volunteer themselves to help the victims. It is a good chance to practice clinical knowledge in emergency situations and decision making. Besides, I also made new friends with the rescue team members and got to know how they rescued the trapped victims. This broadened my knowledge and communication skills. In a disaster, we work as a team and communication is very important to avoid delay in saving lives.

As a medical student and a volunteer, I met flood victims who got affected physically, psychologically, or both. I helped the medical personnel to provide physical care for the patients. Some of them had lost their home or family members and I felt empathy about their condition. I sincerely prayed and hoped that they would be able to walk out of the shadow and start a new life after this. On the other hand, I also hoped the government of Malaysia and non-governmental organisations would help the victims to rebuild new houses and find their lost ones. I learnt many life lessons throughout the volunteering period and learnt to analyse things from different views. Life is unpredictable and we should treasure what we have now. Besides, the volunteering improves my soft skills such as communication and leadership skills. It also improves my clinical knowledge and skills. Therefore, I sincerely hope and urge all medical students worldwide should grab every opportunity to volunteer themselves to make them better doctors in the future!

\section{References}

1. Baharuddin KA, Wahab SFA, Rahman NHNA, Mohamad NAN, Kamaruzaman THT, Nor AYM, and et al. The Record-setting Flood of 2014 in Kelantan: Challenges and Recommendations from an Emergency Medicine Perspective and Why the Medical Campus Stood Dry. Malays J Med Sci. 2015 Mar-Apr;22(2):1-7. 2. Doocy S, Daniels A, Murray S, Kirsch TD. The Human Impact of Floods: a Historical Review of Events 1980-2009 and Systematic Literature Review. PLoS Curr. 2013 Apr 16;5. pii: ecurrents.dis.f4deb457904936bo7cogdaa98ee8171a. 3. Ahern M , Kovats R.S, Wilkinson P, Few R, Matthies F. Global Health Impacts of Floods: Epidemiologic Evidence. Epidemiol Rev. 2005 July;27 (1):36-46. 4. Bich TH, Quang LN, Ha LTT, Hanh TTD, Guha-Sapir D. Impacts of flood on health: epidemiologic evidence from Hanoi, Vietnam. Glob Health Action. 2011;4:6356. 5. Lastoria B, Simonetti MR, Casaioli M. Socio-economic impacts of major floods in Italy from 1951 to 2003. Adv Geosci. 2006;7:223-229.

\section{Acknowledgments}

I would like to express gratitude to the doctors, nurses, rescue team members, governments, non-governmental organisations and everyone who had helped the flood victims during the massive flood period in Kelantan in end of 2014.

Conflict of Interest Statement at Funding

The author has no funding, financial relationships or conflicts of interest to disclose.

\section{Author Contributions}

Conception and design the work/idea, Write the manuscript, Critical revision of the manuscript, Approval of the final version: DDS.

Cite as:

Chong ZX. Experience of a Medical Student: Volunteering in the Emergency Department during Massive Flood in Kelantan, Malaysia. Int J Med Students. 2015 Sep-Dec;3(3):163-4. 